\title{
Identification of the Acinetobacter
} baumannii Ribonuclease P Catalytic Subunit: Cleavage of a Target mRNA in the Presence of an External Guide Sequence

\section{OPEN ACCESS}

Edited by:

Rustam Aminov,

University of Aberdeen, United Kingdom

Reviewed by:

Rosalia Cavaliere,

University of Technology Sydney,

Australia

Lisa Sedger,

University of Technology Sydney,

Australia

*Correspondence:

Marcelo E. Tolmasky

mtolmasky@fullerton.edu

${ }^{\dagger}$ Present address:

Carol Davies-Sala,

Instituto de Investigaciones en

Ingeniería Genética y Biología

Molecular "Dr. Héctor N. Torres", CONICET, Buenos Aires, Argentina

Specialty section:

This article was submitted to Infectious Diseases,

a section of the journal

Frontiers in Microbiology

Received: 17 April 2018

Accepted: 20 September 2018

Published: 08 October 2018

Citation:

Davies-Sala C, Jani S,

Zorreguieta $A$ and Tolmasky ME (2018) Identification of the

Acinetobacter baumannii Ribonuclease $P$ Catalytic Subunit:

Cleavage of a Target mRNA

in the Presence of an External Guide

Sequence. Front. Microbiol. 9:2408.

doi: 10.3389/fmicb.2018.02408

\section{Carol Davies-Sala ${ }^{1,2,3+}$, Saumya Jani ${ }^{1}$, Angeles Zorreguieta ${ }^{2,3}$ and Marcelo E. Tolmasky ${ }^{1 *}$}

${ }^{1}$ Center for Applied Biotechnology Studies, College of Natural Sciences and Mathematics, California State University, Fullerton, Fullerton, CA, United States, ${ }^{2}$ Fundación Instituto Leloir, IIBBA-CONICET, Buenos Aires, Argentina, ${ }^{3}$ Facultad de Ciencias Exactas y Naturales de la Universidad de Buenos Aires, University of Buenos Aires, Buenos Aires, Argentina

The bacterial ribonuclease $\mathrm{P}$ or RNase $\mathrm{P}$ holoenzyme is usually composed of a catalytic RNA subunit, M1, and a cofactor protein, C5. This enzyme was first identified for its role in maturation of tRNAs by endonucleolytic cleavage of the pre-tRNA. The RNase P endonucleolytic activity is characterized by having structural but not sequence substrate requirements. This property led to development of EGS technology, which consists of utilizing a short antisense oligonucleotide that when forming a duplex with a target RNA induces its cleavage by RNase P. This technology is being explored for designing therapies that interfere with expression of genes, in the case of bacterial infections EGS technology could be applied to target essential, virulence, or antibiotic resistant genes. Acinetobacter baumannii is a problematic pathogen that is commonly resistant to multiple antibiotics, and EGS technology could be utilized to design alternative therapies. To better understand the $A$. baumannii RNase $P$ we first identified and characterized the catalytic subunit. We identified a gene coding for an RNA species, M1 $\mathrm{Ab}$, with the expected features of the RNase P M1 subunit. A recombinant clone coding for $\mathrm{M}^{1} 1_{\mathrm{Ab}}$ complemented the M1 thermosensitive mutant Escherichia coli BL21(DE3) T7A49, which upon transformation was able to grow at the non-permissive temperature. $\mathrm{M}^{\mathrm{Ab}}$ showed in vitro catalytic activity in combination with the C5 protein cofactor from $E$. coli as well as with that from $A$. baumannii, which was identified, cloned and partially purified. $\mathrm{M1}_{\mathrm{Ab}}$ was also able to cleave a target mRNA in the presence of an EGS with efficiency comparable to that of the E. coli M1, suggesting that EGS technology could be a viable option for designing therapeutic alternatives to treat multiresistant $A$. baumannii infections.

Keywords: RNase P, Acinetobacter, ESKAPE, ribozyme, EGS technology, antisense

\section{INTRODUCTION}

Ribonuclease $\mathrm{P}$, or RNase $\mathrm{P}$, is a ubiquitous ribozyme that was first identified for its participation in the maturation of the precursor tRNA (pre-tRNA) by endonucleolytic cleavage at the $5^{\prime}$-end of the molecule (Robertson et al., 1972). Later, it was shown that RNase P participates in other biological processes like the synthesis of other RNA species such as transfer messenger RNA, 
precursors to 4.5S RNA, some multicistronic mRNAs, small noncoding RNA genes, phage-related RNAs, and others (Bothwell et al., 1976; Alifano et al., 1994; Komine et al., 1994; Hartmann et al., 1995; Reiner et al., 2006; Yang and Altman, 2007; Jarrous and Gopalan, 2010; Altman, 2011; Klemm et al., 2016). The RNase P holoenzyme is a ribonucleoprotein composed by the RNA molecule responsible for its catalytic activity, known as $\mathrm{M} 1$ in Escherichia coli $\left(\mathrm{M} 1_{\mathrm{Ec}}\right)$, and one or more proteins that act as cofactors (Guerrier-Takada et al., 1983; Marvin and Engelke, 2009; Jarrous, 2017). In particular, bacterial RNase P holoenzymes usually contain only one small cofactor protein, called C5 in E. coli (C5 $\mathrm{Ec}_{\mathrm{Ec}}$ ) (Reiter et al., 2010; Mondragon, 2013). Numerous studies on the RNase P enzymes from different organisms belonging to all three life domains showed many common structural features among the RNA components and a common core with similar secondary structure (Chen and Pace, 1997; Mondragon, 2013). Three types of RNA components of RNase $\mathrm{P}$ were identified in bacteria, the most common are known as types A (for ancestral) and B (for Bacillus); type C includes RNA molecules from green non-sulfur bacteria (Haas and Brown, 1998). For a comparative structural diagram among all three types see the review by Mondragon (Mondragon, 2013). The RNA components of bacterial RNase P include two domains, one of them called $\mathrm{C}$ (catalytic) that recognizes the acceptor stem and the $3^{\prime}$-CCA sequence of the substrate RNA and mediates the endonucleolytic cleavage. The other domain is called S (specificity) and is responsible for substrate recognition (Mondragon, 2013). Crystallographic studies on bacterial RNase $\mathrm{P}$ are limited, only the three-dimensional structures of the intact Thermotoga maritima RNA component and a fragment including the C domain of that of Bacillus stearothermophilus are available (Kazantsev et al., 2005; Torres-Larios et al., 2005). However, although not at the structural level, the E. coli RNase P, which consists of the 377-nucleotides catalytic RNA subunit $\mathrm{M} 1_{\mathrm{Ec}}$ and the 119-amino acids cofactor protein $\mathrm{C} 5_{\mathrm{Ab}}$, is one of the best characterized (Guerrier-Takada et al., 1983). RNase P requires a particular structure in the substrate RNA that includes a doublestranded region (acceptor stem) followed by a single-stranded stretch that includes the RCCA sequence at the $3^{\prime}$ end, which facilitates interaction with the enzyme (Figure 1). One of the two complementary segments of the acceptor stem is called "external guide sequence" (EGS) and is instrumental in guiding RNase $\mathrm{P}$ to cleave the opposite strand during the maturation process (Figure 1). With the exception of the acceptor stem, most other regions of the substrate RNA can be deleted without completely abolishing RNase P activity and, although essential for cleavage, the EGS is not required to be tethered to the rest of the molecule (Forster and Altman, 1990; Gopalan et al., 2002; Figure 1). Furthermore, cleavage is not dependent on the sequence of the substrate (Figure 1). This finding was the foundation of the EGS technology, a gene silencing strategy in which a short oligomer (EGS) interacts with a target RNA, usually mRNA, and elicits its cleavage, interfering with expression of the gene (Lundblad and Altman, 2010). EGS Technology approaches have been explored as alternatives to design therapeutic tools or antibiotic adjuvants for treatment of multidrug resistant bacterial infections (Guerrier-Takada et al., 1997; Soler Bistue
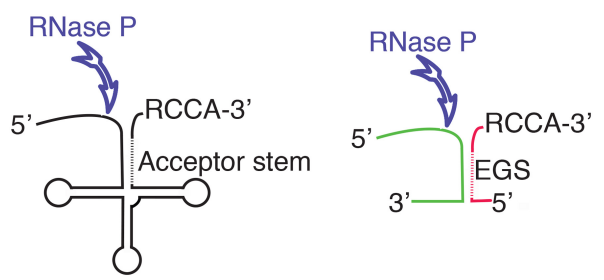

FIGURE 1 | Diagram showing the structure of the pre-tRNA and the location of the endonucleolytic cleavage by RNase P (left). The diagram to the right shows a complex between two RNA molecules with a complementary region that form the appropriate structure to be recognized as substrate by RNase P. The different colors illustrate the fact that while there are structural requirements, $\mathrm{RNase} P$ does not show specificity of sequence. The antisense regions in the acceptor stem and the EGS are shown as dashed lines. The RCCA sequence facilitates the interaction between the substrate and RNase P.

et al., 2007, 2009; Ko et al., 2008; Shen et al., 2009; Sawyer et al., 2013).

Acinetobacter baumannii is a nosocomial pathogen that belongs to the ESKAPE group of pathogens and causes a wide range of severe infections, mainly among immunocompromised patients (Wong et al., 2017; Harding et al., 2018). Treatment of these infections is complicated by the multidrug-resistant nature of most strains, a characteristic that led to inclusion of A. baumannii in the priority list of antibiotic-resistant bacteria by the World Health Organization (Doi et al., 2017; Tacconelli et al., 2018; Tacconelli and Magrini, 2018). As a consequence, there is a high need for new treatments of $A$. baumannii and development of EGSs that inhibit expression of essential functions or antibiotic-resistance genes could be an alternative (Sala et al., 2012). A better understanding of the A. baumannii RNase P will be beneficial for EGS Technology development of therapies to treat multidrug resistant infections caused by this bacterium.

\section{MATERIALS AND METHODS}

\section{Bacterial Strains and Plasmids}

Acinetobacter baumannii ATCC 17978 (Smith et al., 2007) was used as source of genomic DNA and the primers were designed using the complete genome sequence (Accession No. CP000521.1). E. coli DH5 $\alpha$ (Taylor et al., 1993) and BL21(DE3) (Studier et al., 1990) were used as hosts for cloning experiments. E. coli BL21(DE3) T7A49 is a thermosensitive M1 mutant (Guerrier-Takada et al., 1995). Plasmid pM1Ab was generated by inserting a DNA fragment including the A. baumannii $r n p B$ gene $\left(r n p B_{\mathrm{Ab}}\right)$ under the control of the T7 promoter into the cloning vector pCR2.1 (Life Technologies). This fragment was an amplicon generated using A. baumannii ATCC 17978 chromosomal DNA as template and the primers 5' GCAAGCTTTAATACGACTCACTATAGGGGAAGTGAGCCG GATGGTC-3' (the T7 promoter is underlined) and $5^{\prime}$ GCAGGATCCAGGTGAAGTGAGCCTATAAGCC- $3^{\prime}$. The sequence of EGSA2 was 5'-CGAUAUGAGAUCGACCA-3'. 
Plasmid pC5Ab was generated by ligating an amplicon including the A. baumannii rnpA gene $\left(r n p A_{\mathrm{ab}}\right)$ to $N d e \mathrm{I}$ and XhoI-digested pET22(+) (Novagen). The amplicon was obtained using the primers 5'-GCCCATATGGTGCATCAACCCCATTTTTT-3' and $5^{\prime}$-GAACTCGAGATTCTGCGAGGTTGGGACA-3'. The recombinant plasmid $\mathrm{pC} 5 \mathrm{Ab}$ codes for the A. baumannii $\mathrm{C} 5$ $\left(\mathrm{C} 5_{\mathrm{Ab}}\right)$ protein fused to a His-tag at the $\mathrm{C}$-terminus under the control of the $\mathrm{T} 7$ promoter.

\section{General Procedures}

Plasmid DNA preparations were carried out using the Wizard ${ }^{\circledR}$ Plus SV Minipreps DNA Purification System (Promega). Endonuclease restriction and ligase treatments were performed according to the recommendations of the supplier (New England Biolabs). Polymerase chain reactions were carried out using Taq DNA Polymerase (Invitrogen) and the primers indicated (purchased from IDT Technologies), following the supplier's recommendations. In vitro synthesis of RNA molecules was done using a MEGAshortscript high-yield transcription T7 kit according to the protocols provided by the supplier (Ambion). Denaturing polyacrylamide gel electrophoresis was performed as described previously (Sarno et al., 2003) on 6\% polyacrylamide 19:1 (acrylamide-bis-acrylamide), gels containing $7 \mathrm{M}$ urea using a Tris-Borate-EDTA buffer (TBE) or glycerol-tolerant gel (GTG) buffer. Electrophoresis of an aliquot of the $M 1_{A b}$ purified transcript is shown in Supplementary Figure S1A. DNA and RNA sequence analyses were carried out using Basic local alignment search tool (BLAST) (Altschul et al., 1990), MUSCLE (Edgar, 2004), and Bcheck (Yusuf et al., 2010). E. coli M1 (M1 Ec) and $\mathrm{C} 5\left(\mathrm{C} 5_{\mathrm{Ec}}\right)$ were purified as described before (GuerrierTakada et al., 1983).

Overexpression of $\mathrm{C}_{\mathrm{Ab}}$ was carried out culturing E. coli BL21 (DE3; pC5Ab) in LB broth containing $100 \mu \mathrm{g}$ of ampicillin/ml at $37^{\circ} \mathrm{C}$ until the optical density at $600 \mathrm{~nm}$ (OD600) was 0.8 . At this point isopropyl $\beta$-D-galactopyranoside (IPTG) was added to a concentration of $0.5 \mathrm{mM}$, the culture was incubated for $90 \mathrm{~m}$ at $28^{\circ} \mathrm{C}$, and the cells were harvested by centrifugation and suspended in phosphate buffer saline (PBS) buffer $(20 \mathrm{mM}$ sodium phosphate and $300 \mathrm{mM}$ sodium chloride) $\mathrm{pH}$ 7.4. Cells were lysed by French press at 1000 psi (three passages) followed by centrifugation at $4000 \mathrm{~g}$ at $4^{\circ} \mathrm{C}$ for $15 \mathrm{~min}$ to remove cell debris. The supernatant was centrifuged at $13500 \mathrm{~g}$ at $4^{\circ} \mathrm{C}$ for $20 \mathrm{~min}$ and the supernatant was subjected to one last centrifugation at $100000 \mathrm{~g}$ for $1 \mathrm{~h}$ at $4^{\circ} \mathrm{C}$. The supernatant containing the soluble fraction was used for purification of $\mathrm{C} 5_{\mathrm{Ab}}$. The protein was purified by immobilized metal affinity chromatography (IMAC) using a nickel-charged nitrilotriacetic acid (NTA) resin column (Thermo Scientific HisPur Ni-NTA Spin Columns) following the recommendations of the supplier. Once eluted using PBS containing $250 \mathrm{mM}$ imidazole and $6 \mathrm{M}$ Guanidine $\mathrm{HCl}, \mathrm{pH}$ 7.4, the samples were dialyzed against $\mathrm{PBS}$ at $4^{\circ} \mathrm{C}$. Proteins were analyzed using sodium dodecyl sulfate $15 \%$ polyacrylamide gel electrophoresis (SDSPAGE)(Laemmli, 1970) followed by staining with Coomassie Brilliant Blue. Nucleotide and amino acid sequence analyses and comparisons were performed using the Clustal Omega and the BLAST programs (Altschul et al., 1990; Sievers et al., 2011).
The prediction of physical and chemical parameters, search of specific domains, and modeling were carried out using the ProtParam, Pfam, and SWISS-MODEL, respectively (Gasteiger et al., 2005; Finn et al., 2014; Bienert et al., 2017). An SDS-PAGE analysis of the purified $\mathrm{C} 5_{\mathrm{Ab}}$ protein is shown in Supplementary Figure S1B.

\section{In vitro RNase $\mathrm{P}$ Assays}

Unimolecular substrate: the reaction contained pre-tRNA ${ }^{\text {Tyr }}$ (80 pmol), $\mathrm{M} 1_{\mathrm{Ec}}$ or $\mathrm{M} 1_{\mathrm{Ab}}(40 \mathrm{pmol}), \mathrm{C} 5_{\mathrm{EC}}$ or $\mathrm{C} 5_{\mathrm{Ab}}$ (50 pmol; when indicated) in C5 buffer (20 mM HEPES-KOH $\mathrm{pH}=8$, $400 \mathrm{mM}$ ammonium acetate, $10 \mathrm{mM}$ magnesium acetate, $5 \%$ glycerol) in a total volume of $10 \mu$. Incubation was performed at $37^{\circ} \mathrm{C}$ for $90 \mathrm{~m}$. Bimolecular substrate: $\operatorname{aac}(6)^{\prime}$ Ib mRNA (40 pmol) was incubated with EGS (50 pmol) at room temperature for $15 \mathrm{~min}$. Simultaneously, $\mathrm{M}_{\mathrm{Ab}}(40 \mathrm{pmol})$ was incubated with $\mathrm{C}_{\mathrm{Ec}}(50 \mathrm{pmol})$ in $\mathrm{C} 5$ buffer at $37^{\circ} \mathrm{C}$ for $15 \mathrm{~min}$. Both fractions were combined and incubated for $90 \mathrm{~min}$ at $37^{\circ} \mathrm{C}$. The reaction was stopped by heating and subjected to phenol/chloroform extraction followed by ethanol precipitation as described before (Jani et al., 2018). The products were resuspended in 1 volume of gel loading buffer and analyzed by $6 \%$ denaturing TBE-PAGE or GTG-PAGE (Soler Bistue et al., 2009). RNA bands were visualized by staining with ethidium bromide and UV transillumination.

\section{M1 Heterologous Complementation Assays}

Escherichia coli BL21(DE3) T7A49 and E. coli BL21(DE3) T7A49 (pM1Ab) were incubated in LB broth for $24 \mathrm{~h}$ at 28 or $42^{\circ} \mathrm{C}$, with or without $0.1 \mathrm{mM}$ IPTG. Bacterial growth was determined by measuring $\mathrm{OD}_{600}$. Assays were carried out in duplicate and repeated three times. Statistical significance was analyzed by oneway ANOVA with Dunnett's multiple comparison test. $P<0.05$ was considered statistically significant.

\section{RESULTS AND DISCUSSION}

A BLAST search using as query the E. coli $r n p B$ nucleotide sequence (Accession No. NCBI Gene ID 947634) and the complete genome of A. baumannii ATCC 17978 as subject (Accession No. GenBank: CP000521.1) identified a region (coordinates 987928-988235) with $80 \%$ identity to the E. coli $\operatorname{rnpB}$ that was called $r m p B_{\mathrm{Ab}}$. A comparative analysis of the nucleotide sequence of this region to the $r n p B$ genes from $E$. coli and Klebsiella pneumoniae (Accession No. GenBank: M32719.1) (Lawrence et al., 1987) permitted us to determine the $r p p B_{\mathrm{Ab}}$ promoter region as well as the first and last nucleotide of the RNA molecule encoded, called $\mathrm{M}_{\mathrm{Ab}}$ (Figure 2A). Inspection of the $M 1_{\mathrm{Ab}}$ sequence shows that it belongs to the type $\mathrm{A}$ group of RNase P catalytic subunits and includes the conserved regions (Chen and Pace, 1997; Mondragon, 2013). Further analysis using Bcheck (Yusuf et al., 2010) identified the $M 1_{A b}$ sequence as an RNase P RNA. The high level of identity between the sequence of $r n p B_{\mathrm{Ab}}$ and those from the $r m p B$ genes from $E$. coli and $K$. pneumoniae extends from the -10 nucleotide 
A
A. baumannii
K. pneumoniae
E. coli

\section{A. baumannii \\ K. pneumoniae \\ E. coli}
A. baumannii
K. pneumoniae
E. coli
A. baumannii
K. pneumoniae
E. coli
A. baumannii
K. pneumoniae
E. coli

\section{A. baumannii \\ K. pneumoniae \\ E. coli}

\section{A. baumannii \\ K. pneumoniae \\ E. coli}

GAAGTGAGCCGGATGGTCGCTGCTGTGGAGGTCTCC - . - . - . - GTGACTGAAGCAG GAAGCTGACCAGACAGTCGCCGCTTCGTCGTCGTCCTCCTTCGGGGGGAGACGGGCGGAG GAAGCTGACCAGACAGTCGCCGCTTCGTCGTCGTCCTCTTC- -GGGGGAGACGGGCGGAG $* * * * \quad * * * * * * * * * * * * * * * * * * * * *$ CRI

GAGAGGAAAGTCCGGGCTTCATAGGGCAGGGTGCCAGGTAACGCCTGGGCGGTG- - AAAG GGGAGGAAAGTCCGGGCTCCATAGGGCAAGGTGCCAGGTAACGCCTGGGGGGTGTCACGA GGGAGGAAAGTCCGGGCTCCATAGGGCAGGGTGCCAGGTAACGCCTGGGGGG - - - - GAAA

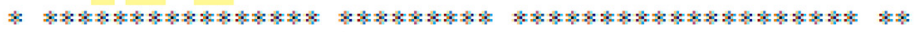
CRII

CCGACGGAAAGTGCAGCAGAGAGTAGACCGCC - TCATTCGTG- . . . . . - AGGTAA CCCACGACCAGTGCAACAGAGAGCAAACCGCCGATGGCCCGCGCAAGCGGGATCAGGTAA CCCACGACCAGTGCAACAGAGAGCAAACCGCCGATGGCCCGCGCAAGCGGGATCAGGTAA

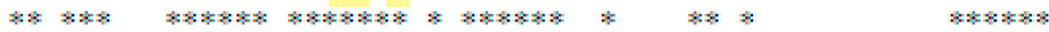
CRIII

GGGTGAAAGGGTGCGGTAAGAGCGCACCGCGTGTCTGGTAACAGTTCACGGCATGGCAAA GGGTGAAAGGGTGCGGTAAGAGCGCACCGCGCGGCTGGTAACAGTCCGCGGCACGGTAAA GGGTGAAAGGGTGCGGTAAGAGCGCACCGCGCGGCTGGTAACAGTCCGTGGCACGGTAAA

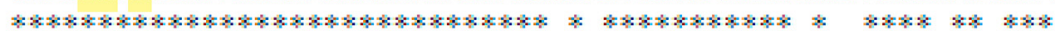
CCCCACCAGAAGCAAGACCAAATAGGAATCC - -TAGGTGCGGCCCGTACTGGATTCGGGT CTCCACCCGGAGCAAGGCCAAATAGGGGTTCATAAGGTACGGCCCGTACTGAACCCGGGT CTCCACCCGGAGCAAGGCCAAATAGGGGTTCATAAGGTACGGCCCGTACTGAACCCGGGT

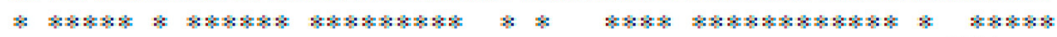
CRIV CRV

AGGTCGCTTGAGCGTATGAGTGATTGTACGCCTAGAGGAATGACCATCCTCGACAGAACC AGGCTGCTTGAGCCAGTGAGCGATTGCTGGCCTAGATGAATGACTGTCCACGACAGAACC AGGCTGCTTGAGCCAGTGAGCGATTGCTGGCCTAGATGAATGACTGTCCACGACAGAACC

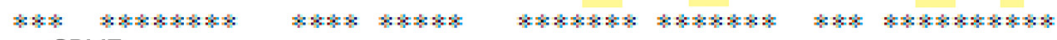
CRVI

CGGCTTATAGGCTCACTTCACCT CGGCTTATCGGTCAGTTTCACCT CGGCTTATCGGTCAGTTTCACCT

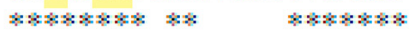

B

\begin{tabular}{|c|c|c|c|c|c|c|}
\hline & & -35 & & -10 & & +1 \\
\hline A. baumanni & CAAAAAAGCAC & AAGCAA & TTAGTCAATAAATTTGT & TAATAT & GCGCCCTC & GAA \\
\hline nnoumpn & TACCACTAGGG & ATGACA & ACGGGCGGTAAACCCTC & TATACT & GCGCGC-C & GAA \\
\hline $\operatorname{col} i$ & CGCAACGCGGG & GTGACA & AGGGCGCGCAAACCCTC & TATACT & GCGCGC-C & GAA \\
\hline
\end{tabular}

FIGURE 2 | Alignment of the nucleotide sequences of the coding and promoter regions of RNA subunit (M1) of the ribonuclease P from Escherichia coli, Klebsiella pneumoniae, and Acinetobacter baumannii. (A) Multiple alignment of the coding sequences of M1 performed using MUSCLE. The yellow rectangles show nucleotides belonging to the universally Conserved Regions present in RNA subunits of RNase P (Chen and Pace, 1997), each region is indicated in roman numbers. (B) Alignment of the promoter regions.

in the promoter region (Lawrence et al., 1987) to the $3^{\prime}$ end of the RNA molecule. Conversely, the -35 and spacer regions show divergence (Figure 2B). This could be a consequence of adaptation to different properties between the RNA polymerases from A. baumannii and the two Enterobacteriaceae. Future comparative studies of expression and activity levels in all three bacteria may lead to a better understanding of the significance of these differences.

The $r m p B_{\mathrm{Ab}}$ gene was cloned under the control of the T7 promoter and the 355-nt $\mathrm{Ml}_{\mathrm{Ab}}$ RNA was synthesized in vitro as described in section "Materials and Methods" (Supplementary Figure S1A). The synthesized product was tested to determine its RNase $\mathrm{P}$ activity using as substrate pretRNA ${ }^{\text {Tyr }}$. Figure 3 shows that both $M 1_{A b}$ and the $M 1_{E c}$ cleaved the substrate with similar efficiency in the presence of the cofactor protein $\mathrm{C}_{\mathrm{Ec}}$ and were inactive in the absence of the protein in the conditions used in the assay. Previous work carried out with M1 showed that at certain magnesium concentrations in vitro, cleavage occurs in the absence of C5 (Guerrier-Takada et al., 1983). The results of the experiment shown in Figure 3 not 

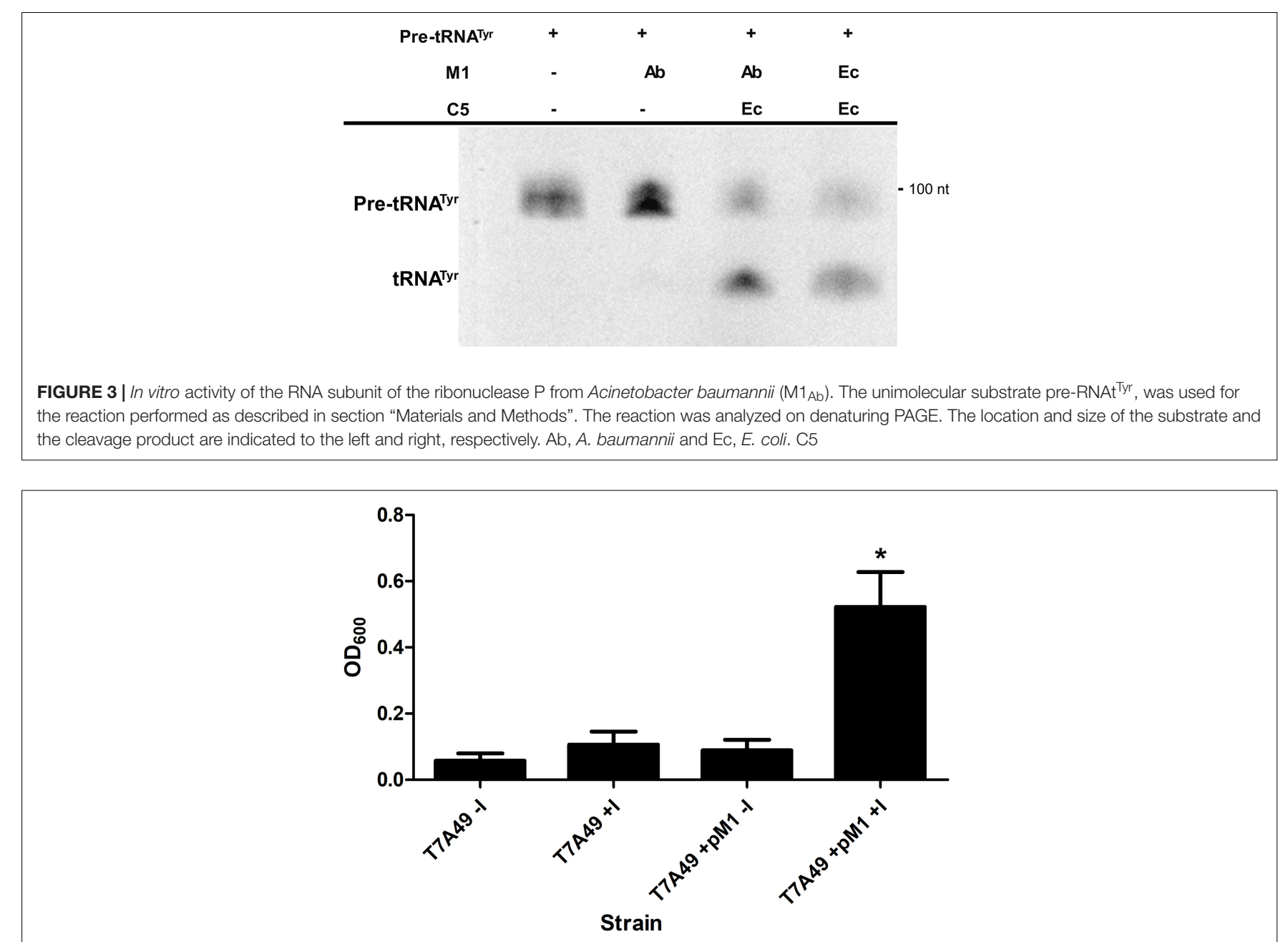

FIGURE 4 | Heterologous complementation of strain E. coli BL21(DE3) T7A49. The M1 EC thermosensitive mutant was transformed with pM1Ab, a plasmid encoding $\mathrm{M}_{\mathrm{Ab}}$ under the control of a T7 promoter. E. coli BL21(DE3) T7A49 (T7A49) and E. coli BL21(DE3) T7A49 (pM1Ab) (T7A49M1) were cultured in the presence (IPTG) or absence of $0.1 \mathrm{mM}$ IPTG Growth was assessed measuring $\mathrm{OD}_{600}$. Statistical analysis was carried out using one-way ANOVA and Dunnett's multiple comparison test. *indicates statistical significance $(P<0.05)$.

only confirmed that the $\mathrm{M} 1_{\mathrm{Ab}}$ RNA is the A. baumannii RNase $\mathrm{P}$ catalytic subunit, but also that it is active in the presence of a heterologous cofactor as it is the $\mathrm{C}_{\mathrm{Ec}}$ protein. To confirm the activity of $\mathrm{M}_{\mathrm{Ab}}$ in vivo, we carried out an experiment using the M1 thermosensitive mutant E. coli BL21(DE3) T7A49, which does not grow at the non-permissive temperature $\left(42^{\circ} \mathrm{C}\right)$. This strain was transformed with the plasmid $\mathrm{pM} 1 \mathrm{Ab}$ and the transformant strain was cultured at 28 and $42^{\circ} \mathrm{C}$ in the presence or absence of IPTG. Figure 4 shows that the E. coli BL21(DE3) T7A49(pM1Ab) acquired the ability to grow at $42^{\circ} \mathrm{C}$ when expression of $\mathrm{M} 1_{\mathrm{Ab}}$ was induced by addition of IPTG, indicating that RNase P function was restored. This result showed that, as it was the case for the in vitro reaction, $\mathrm{M} 1_{\mathrm{Ab}}$ could interact with $\mathrm{C} 5_{\mathrm{Ec}}$ and produce a functional RNase $\mathrm{P}$ in vivo.

Studies on the RNase $\mathrm{P}$ showed that most of the pretRNA substrate molecule could be removed without affecting its activity (Gopalan et al., 2002; Lundblad and Altman, 2010). Furthermore, bimolecular complexes were also substrates as long as they form the appropriate structure regardless of the nucleotide sequence (Gopalan et al., 2002; Lundblad and Altman, 2010). These findings originated what is known as EGS technology, which takes advantage of the host RNase $\mathrm{P}$ activity to induce degradation of a target mRNA in the presence of an antisense oligonucleotide known as EGS (Gopalan et al., 2002; Lundblad and Altman, 2010; Davies-Sala et al., 2015). This technology could be an option for designing antimicrobials that target essential A. baumannii functions or adjuvants that inhibit expression of resistance genes and would be used in combination with the appropriate antibiotic to restore its therapeutic power. We assessed the ability of $M 1_{A b}$ to elicit cleavage of a target mRNA in the presence of an EGS (bimolecular RNA substrate) in comparison to that of $\mathrm{M} 1_{\mathrm{EC}}$. For this we used a bimolecular substrate consisting of the $a a c\left(6^{\prime}\right)-I b$ mRNA, which codes for an acetyltransferase that catalyzes inactivation of several aminoglycosides of clinical relevance (Ramirez and Tolmasky, 2010; Ramirez et al., 2013), 


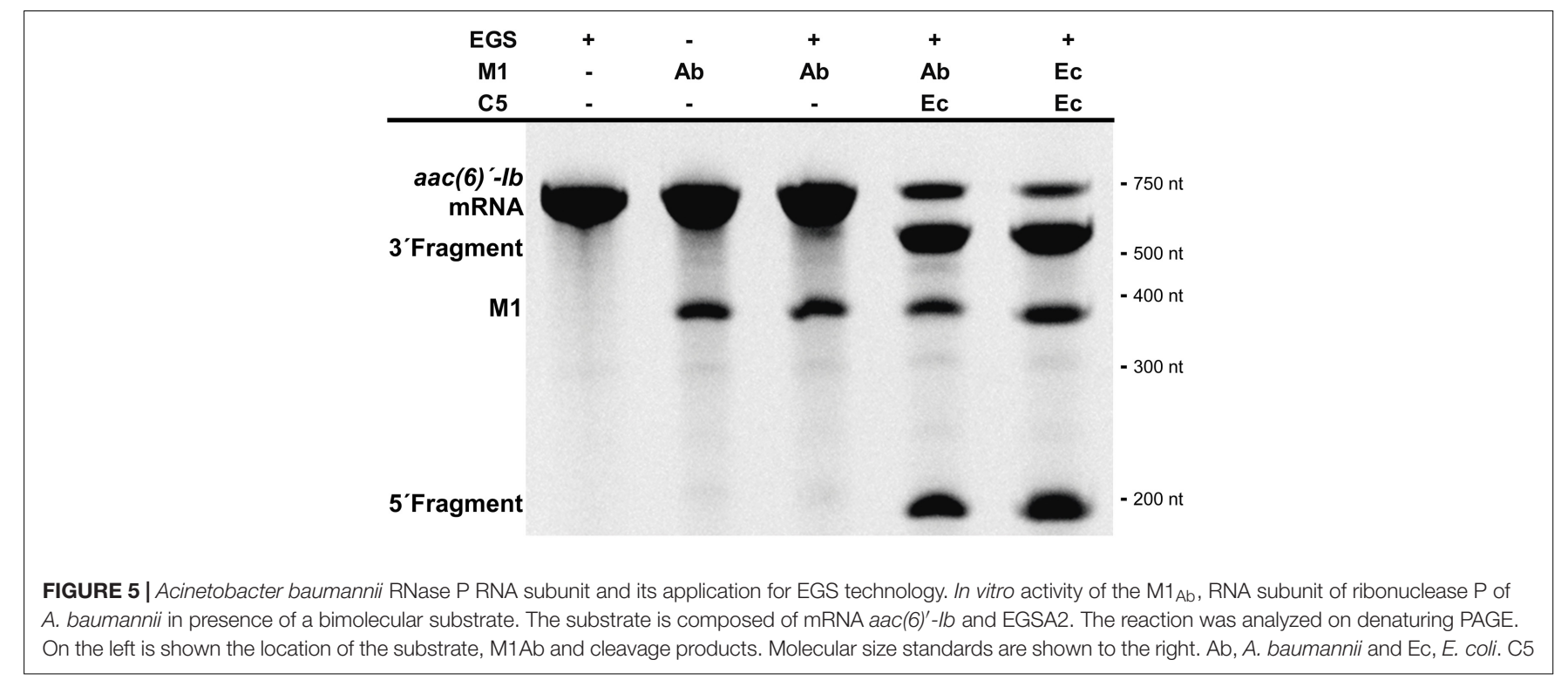

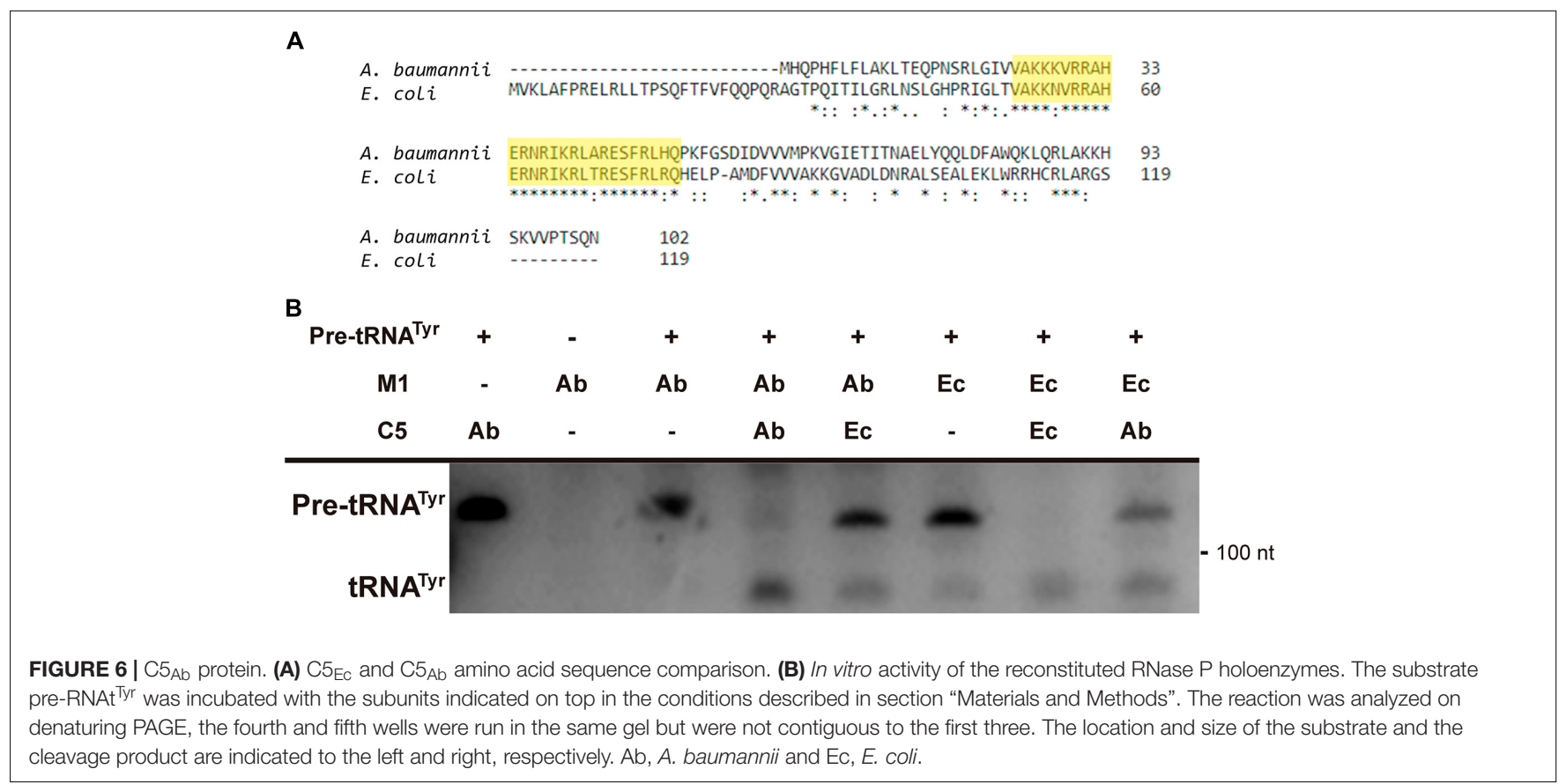

and an EGS, EGSA2, that elicits cleavage of the mRNA by the E. coli RNase P holoenzyme (Soler Bistue et al., 2009). Figure 5 shows that the reactions carried out with both $\mathrm{M} 1_{\mathrm{EC}}$ and $\mathrm{M} 1_{\mathrm{Ab}}$ produced the same level of degradation of the $a a c\left(6^{\prime}\right)-I b$ mRNA strongly suggesting that EGS technology could be an alternative for novel treatments of $A$. baumannii infections.

Further analysis of the A. baumannii ATCC17978 genome sequence permitted us to identify an open reading frame potentially coding for $\mathrm{C}_{\mathrm{Ab}}$, the A. baumannii RNase P cofactor protein. Amino acid sequence comparison between the $\mathrm{C} 5_{\mathrm{Ec}}$ and $\mathrm{C} 5_{\mathrm{Ab}}$ proteins showed low similarity throughout most of the sequence. However, a shared conserved 30-amino acid central core characteristic of C5 proteins was identified (Figure 6A, highlighted in yellow). The $\mathrm{C}_{\mathrm{Ab}}$ predicted isoelectric point was 10.8 , characteristic of nucleic acids-binding proteins. Pfam analysis predicted this protein to possess a domain (amino acids $2-86)$ corresponding to cofactors of RNase $\mathrm{P}$ family proteins. The $C 5_{\mathrm{Ab}}$ protein was used to reconstitute the $A$. baumannii holoenzyme. Figure $6 \mathrm{~B}$ shows that $\mathrm{M} 1_{\mathrm{Ab}}$ or $\mathrm{M} 1_{\mathrm{Ec}}$ were activated in the presence of $\mathrm{C} 5_{\mathrm{Ab}}$ when tested using pre-tRNA ${ }^{\text {tyr }}$ as substrate.

In conclusion, the results described in this study indicate that we identified the A. baumannii ATCC 17978 RNase P gene coding for the catalytic subunit, $\mathrm{M}_{\mathrm{Ab}}$, and showed that its activity is comparable to that of the E. coli M1 subunit. 
$\mathrm{M} 1_{\mathrm{Ab}}$ was functional in the presence of $\mathrm{C} 5_{\mathrm{Ec}}$ as well as $\mathrm{C} 5_{\mathrm{Ab}}$, the latter of which was partially purified after the gene was identified and cloned. Furthermore, the $\mathrm{M} 1_{\mathrm{Ab}}$ ability to cleave otherwise non-substrate target mRNAs in the presence of an adequate EGS indicates that EGS technology could be a viable option for designing therapeutic alternatives to treat multiresistant A. baumannii infections. However, numerous challenges remain to be addressed before this technique can be reduced to practice. Non-hydrolyzable, but active analogs must be designed to ensure stability. Also, the compound must efficiently penetrate the cells once it reached the site of infection. Promising but still preliminary results have been obtained testing conjugates between nuclease resistant hybrid locked nucleic acids (LNA)/DNA oligomers and the cell penetrating peptide (RXR) ${ }_{4} \mathrm{XB}$ (where $\mathrm{R}$ stands for arginine, $\mathrm{X}$ for 6-aminohexanoic acid, and B for beta-alanine) (Jackson et al., 2016; Jani et al., 2018). Although previous reports indicate that antisense compounds containing LNA and DNA nucleotides show low toxicity (Wahlestedt et al., 2000), once a specific compound is identified as a candidate for treatment of A. baumannii infections, its cytotoxicity will have to be determined.

\section{REFERENCES}

Alifano, P., Rivellini, F., Piscitelli, C., Arraiano, C. M., Bruni, C. B., and Carlomagno, M. S. (1994). Ribonuclease E provides substrates for ribonuclease P-dependent processing of a polycistronic mRNA. Genes Dev. 8, 3021-3031. doi: 10.1101/gad.8.24.3021

Altman, S. (2011). Ribonuclease P. Philos. Trans. R. Soc. Lond. B Biol. Sci. 366, 2936-2941. doi: 10.1098/rstb.2011.0142

Altschul, S. F., Gish, W., Miller, W., Myers, E. W., and Lipman, D. J. (1990). Basic local alignment search tool. J. Mol. Biol. 215, 403-410. doi: 10.1016/S00222836(05)80360-2

Bienert, S., Waterhouse, A., de Beer, T. A., Tauriello, G., Studer, G., Bordoli, L., et al. (2017). The SWISS-MODEL repository-new features and functionality. Nucleic Acids Res. 45, D313-D319. doi: 10.1093/nar/gkw1132

Bothwell, A. L., Garber, R. L., and Altman, S. (1976). Nucleotide sequence and in vitro processing of a precursor molecule to Escherichia coli 4.5 S RNA. J. Biol. Chem. 251, 7709-7716.

Chen, J. L., and Pace, N. R. (1997). Identification of the universally conserved core of ribonuclease P RNA. RNA 3, 557-560.

Davies-Sala, C., Soler-Bistue, A., Bonomo, R. A., Zorreguieta, A., and Tolmasky, M. E. (2015). External guide sequence technology: a path to development of novel antimicrobial therapeutics. Ann. N. Y. Acad. Sci. 1354, 98-110. doi: $10.1111 /$ nyas. 12755

Doi, Y., Bonomo, R. A., Hooper, D. C., Kaye, K. S., Johnson, J. R., Clancy, C. J., et al. (2017). Gram-negative bacterial infections: research priorities, accomplishments, and future directions of the antibacterial resistance leadership group. Clin. Infect. Dis. 64(Suppl_1), S30-S35. doi: 10.1093/cid/ ciw829

Edgar, R. C. (2004). MUSCLE: multiple sequence alignment with high accuracy and high throughput. Nucleic Acids Res. 32, 1792-1797. doi: 10.1093/nar/gkh340

Finn, R. D., Bateman, A., Clements, J., Coggill, P., Eberhardt, R. Y., Eddy, S. R., et al. (2014). Pfam: the protein families database. Nucleic Acids Res. 42, D222-D230. doi: 10.1093/nar/gkt1223

Forster, A. C., and Altman, S. (1990). External guide sequences for an RNA enzyme. Science 249, 783-786. doi: 10.1126/science.1697102

Gasteiger, E., Hoogland, C., Gattiker, A., Duvaud, S., Wilkins, M. R., Appel, R. D., et al. (2005). "Protein identification and analysis tools on the ExPASy server," in The Proteomics Protocols Handbook, ed. J. M. Walker (New York, NY: Humana Press), 571-607. doi: 10.1385/1-59259-890-0:571

\section{AUTHOR CONTRIBUTIONS}

AZ, CD-S, and MT conceived and designed the experiments. CD-S and SJ performed the experiments. AZ, CD-S, MT, and SJ analyzed the data. AZ, CD-S, and MT wrote the paper.

\section{FUNDING}

This work was funded by Public Health Service Grant 2R15AI047115-05A1 (to MT) from the National Institutes of Health and X-240 Universidad de Buenos Aires (to AZ). AZ is a career member of Consejo Nacional de Investigaciones Científicas y Técnicas (CONICET). CD-S was supported by a fellowship from CONICET.

\section{SUPPLEMENTARY MATERIAL}

The Supplementary Material for this article can be found online at: https://www.frontiersin.org/articles/10.3389/fmicb. 2018.02408/full\#supplementary-material

Gopalan, V., Vioque, A., and Altman, S. (2002). RNase P: variations and uses. J. Biol. Chem. 277, 6759-6762. doi: 10.1074/jbc.R10006 7200

Guerrier-Takada, C., Gardiner, K., Marsh, T., Pace, N., and Altman, S. (1983). The RNA moiety of ribonuclease P is the catalytic subunit of the enzyme. Cell 35 , 849-857. doi: 10.1016/0092-8674(83)90117-4

Guerrier-Takada, C., Li, Y., and Altman, S. (1995). Artificial regulation of gene expression in Escherichia coli by RNase P. Proc. Natl. Acad. Sci. U.S.A. 92, 11115-11119. doi: 10.1073/pnas.92.24.11115

Guerrier-Takada, C., Salavati, R., and Altman, S. (1997). Phenotypic conversion of drug-resistant bacteria to drug sensitivity. Proc. Natl. Acad. Sci. U.S.A. 94, 8468-8472. doi: 10.1073/pnas.94.16.8468

Haas, E. S., and Brown, J. W. (1998). Evolutionary variation in bacterial RNase P RNAs. Nucleic Acids Res. 26, 4093-4099. doi: 10.1093/nar/26.18. 4093

Harding, C. M., Hennon, S. W., and Feldman, M. F. (2018). Uncovering the mechanisms of Acinetobacter baumannii virulence. Nat. Rev. Microbiol. 16, 91-102. doi: 10.1038/nrmicro.2017.148

Hartmann, R. K., Heinrich, J., Schlegl, J., and Schuster, H. (1995). Precursor of C4 antisense RNA of bacteriophages P1 and P7 is a substrate for RNase P of Escherichia coli. Proc. Natl. Acad. Sci. U.S.A. 92, 5822-5826. doi: 10.1073/pnas. 92.13 .5822

Jackson, A., Jani, S., Sala, C. D., Soler-Bistue, A. J., Zorreguieta, A., and Tolmasky, M. E. (2016). Assessment of configurations and chemistries of bridged nucleic acids-containing oligomers as external guide sequences: a methodology for inhibition of expression of antibiotic resistance genes. Biol. Methods Protoc. 1:bw001. doi: 10.1093/biomethods/bpw001

Jani, S., Jackson, A., Davies-Sala, C., Chiem, K., Soler-Bistue, A., Zorreguieta, A., et al. (2018). Assessment of external guide sequences' (EGS) efficiency as inducers of RNase P-mediated cleavage of mRNA target molecules. Methods Mol. Biol. 1737, 89-98. doi: 10.1007/978-1-4939-7634-8_6

Jarrous, N. (2017). Roles of RNase P and its subunits. Trends Genet. 33, 594-603. doi: 10.1016/j.tig.2017.06.006

Jarrous, N., and Gopalan, V. (2010). Archaeal/eukaryal RNase P: subunits, functions and RNA diversification. Nucleic Acids Res. 38, 7885-7894. doi: 10.1093/nar/gkq701

Kazantsev, A. V., Krivenko, A. A., Harrington, D. J., Holbrook, S. R., Adams, P. D., and Pace, N. R. (2005). Crystal structure of a bacterial ribonuclease P RNA. Proc. Natl. Acad. Sci. U.S.A. 102, 13392-13397. doi: 10.1073/pnas.0506662102 
Klemm, B. P., Wu, N., Chen, Y., Liu, X., Kaitany, K., Howard, M. J., et al. (2016). The diversity of Ribonuclease P: protein and RNA catalysts with analogous biological functions. Biomolecules 6:27. doi: 10.3390/biom6020027

Ko, J. H., Izadjoo, M., and Altman, S. (2008). Inhibition of expression of virulence genes of Yersinia pestis in Escherichia coli by external guide sequences and RNase P. RNA 14, 1656-1662. doi: 10.1261/rna.1120508

Komine, Y., Kitabatake, M., Yokogawa, T., Nishikawa, K., and Inokuchi, H. (1994). A tRNA-like structure is present in 10Sa RNA, a small stable RNA from Escherichia coli. Proc. Natl. Acad. Sci. U.S.A. 91, 9223-9227. doi: 10.1073/pnas. 91.20.9223

Laemmli, U. K. (1970). Cleavage of structural proteins during the assembly of the head of bacteriophage T4. Nature 227, 680-685. doi: 10.1038/227680a0

Lawrence, N. P., Richman, A., Amini, R., and Altman, S. (1987). Heterologous enzyme function in Escherichia coli and the selection of genes encoding the catalytic RNA subunit of RNase P. Proc. Natl. Acad. Sci. U.S.A. 84, 6825-6829. doi: 10.1073/pnas.84.19.6825

Lundblad, E. W., and Altman, S. (2010). Inhibition of gene expression by RNase P. N. Biotechnol. 27, 212-221. doi: 10.1016/j.nbt.2010.03.003

Marvin, M. C., and Engelke, D. R. (2009). RNase P: increased versatility through protein complexity? RNA Biol. 6, 40-42.

Mondragon, A. (2013). Structural studies of RNase P. Annu. Rev. Biophys. 42, 537-557. doi: 10.1146/annurev-biophys-083012-130406

Ramirez, M. S., Nikolaidis, N., and Tolmasky, M. E. (2013). Rise and dissemination of aminoglycoside resistance: the aac(6')-Ib paradigm. Front. Microbiol. 4:121. doi: 10.3389/fmicb.2013.00121

Ramirez, M. S., and Tolmasky, M. E. (2010). Aminoglycoside modifying enzymes. Drug Resist. Updat. 13, 151-171. doi: 10.1016/j.drup.2010.08.003

Reiner, R., Ben-Asouli, Y., Krilovetzky, I., and Jarrous, N. (2006). A role for the catalytic ribonucleoprotein RNase P in RNA polymerase III transcription. Genes Dev. 20, 1621-1635. doi: 10.1101/gad.386706

Reiter, N. J., Osterman, A., Torres-Larios, A., Swinger, K. K., Pan, T., and Mondragon, A. (2010). Structure of a bacterial ribonuclease P holoenzyme in complex with tRNA. Nature 468, 784-789. doi: 10.1038/nature09516

Robertson, H. D., Altman, S., and Smith, J. D. (1972). Purification and properties of a specific Escherichia coli ribonuclease which cleaves a tyrosine transfer ribonucleic acid presursor. J. Biol. Chem. 247, 5243-5251.

Sala, C. D., Soler-Bistue, A. J., Korprapun, L., Zorreguieta, A., and Tolmasky, M. E. (2012). Inhibition of cell division induced by external guide sequences (EGS Technology) targeting ftsZ. PLoS One 7:e47690. doi: 10.1371/journal. pone. 0047690

Sarno, R., Ha, H., Weinsetel, N., and Tolmasky, M. E. (2003). Inhibition of aminoglycoside 6'-N-acetyltransferase type Ib-mediated amikacin resistance by antisense oligodeoxynucleotides. Antimicrob. Agents Chemother. 47, 3296-3304. doi: 10.1128/AAC.47.10.3296-3304.2003

Sawyer, A. J., Wesolowski, D., Gandotra, N., Stojadinovic, A., Izadjoo, M., Altman, S., et al. (2013). A peptide-morpholino oligomer conjugate targeting Staphylococcus aureus gyrA mRNA improves healing in an infected mouse cutaneous wound model. Int. J. Pharm. 453, 651-655. doi: 10.1016/j.ijpharm. 2013.05.041

Shen, N., Ko, J. H., Xiao, G., Wesolowski, D., Shan, G., Geller, B., et al. (2009). Inactivation of expression of several genes in a variety of bacterial species by EGS technology. Proc. Natl. Acad. Sci. U.S.A. 106, 8163-8168. doi: 10.1073/pnas. 0903491106

Sievers, F., Wilm, A., Dineen, D., Gibson, T. J., Karplus, K., Li, W., et al. (2011). Fast, scalable generation of high-quality protein multiple sequence alignments using Clustal Omega. Mol. Syst. Biol. 7:539. doi: 10.1038/msb. 2011.75

Smith, M. G., Gianoulis, T. A., Pukatzki, S., Mekalanos, J. J., Ornston, L. N., Gerstein, M., et al. (2007). New insights into Acinetobacter baumannii pathogenesis revealed by high-density pyrosequencing and transposon mutagenesis. Genes Dev. 21, 601-614. doi: 10.1101/gad.1510307

Soler Bistue, A. J., Ha, H., Sarno, R., Don, M., Zorreguieta, A., and Tolmasky, M. E. (2007). External guide sequences targeting the aac(6')-Ib mRNA induce inhibition of amikacin resistance. Antimicrob. Agents Chemother. 51, 1918-1925. doi: 10.1128/AAC.01500-06

Soler Bistue, A. J., Martin, F. A., Vozza, N., Ha, H., Joaquin, J. C., Zorreguieta, A., et al. (2009). Inhibition of aac(6')-Ib-mediated amikacin resistance by nucleaseresistant external guide sequences in bacteria. Proc. Natl. Acad. Sci. U.S.A. 106, 13230-13235. doi: 10.1073/pnas.0906529106

Studier, F. W., Rosenberg, A. H., Dunn, J. J., and Dubendorff, J. W. (1990). Use of T7 RNA polymerase to direct expression of cloned genes. Methods Enzymol. 185, 60-89. doi: 10.1016/0076-6879(90)85008-C

Tacconelli, E., Carrara, E., Savoldi, A., Harbarth, S., Mendelson, M., Monnet, D. L., et al. (2018). Discovery, research, and development of new antibiotics: the WHO priority list of antibiotic-resistant bacteria and tuberculosis. Lancet Infect. Dis. 18, 318-327. doi: 10.1016/S1473-3099(17)30753-3

Tacconelli, E., and Magrini, N. (2018). Global Priority List of Antibiotic-Resistant Bacteria to Guide Research, Discovery, and Development of New Antibiotics. Geneva: World Health Organization.

Taylor, R. G., Walker, D. C., and McInnes, R. R. (1993). E. coli host strains significantly affect the quality of small scale plasmid DNA preparations used for sequencing. Nucleic Acids Res. 21, 1677-1678. doi: 10.1093/nar/21.7.1677

Torres-Larios, A., Swinger, K. K., Krasilnikov, A. S., Pan, T., and Mondragon, A. (2005). Crystal structure of the RNA component of bacterial ribonuclease P. Nature 437, 584-587. doi: 10.1038/nature04074

Wahlestedt, C., Salmi, P., Good, L., Kela, J., Johnsson, T., Hokfelt, T., et al. (2000). Potent and nontoxic antisense oligonucleotides containing locked nucleic acids. Proc. Natl. Acad. Sci. U.S.A. 97, 5633-5638. doi: 10.1073/pnas.97.10. 5633

Wong, D., Nielsen, T. B., Bonomo, R. A., Pantapalangkoor, P., Luna, B., and Spellberg, B. (2017). Clinical and pathophysiological overview of Acinetobacter infections: a century of challenges. Clin. Microbiol. Rev. 30, 409-447. doi: 10.1128/CMR.00058-16

Yang, L., and Altman, S. (2007). A noncoding RNA in Saccharomyces cerevisiae is an RNase P substrate. RNA 13, 682-690. doi: 10.1261/rna.460607

Yusuf, D., Marz, M., Stadler, P. F., and Hofacker, I. L. (2010). Bcheck: a wrapper tool for detecting RNase P RNA genes. BMC Genomics 11:432. doi: 10.1186/ 1471-2164-11-432

Conflict of Interest Statement: The authors declare that the research was conducted in the absence of any commercial or financial relationships that could be construed as a potential conflict of interest.

Copyright (c) 2018 Davies-Sala, Jani, Zorreguieta and Tolmasky. This is an openaccess article distributed under the terms of the Creative Commons Attribution License (CC BY). The use, distribution or reproduction in other forums is permitted, provided the original author(s) and the copyright owner(s) are credited and that the original publication in this journal is cited, in accordance with accepted academic practice. No use, distribution or reproduction is permitted which does not comply with these terms. 